\section{EDUCAÇÃO FÍSICA NOS ANOS FINAIS DO ENSINO FUNDAMENTAL, SUAS FORMAS E SEUS LUGARES NO CURRÍCULO ESCOLAR: UM ESTUDO DE REVISÃO}

\author{
PHYSICAL EDUCATION IN THE FINAL YEARS OF ELEMENTARY SCHOOL, ITS \\ FORMS AND ITS PLACES IN THE SCHOOL CURRICULUM: A REVIEW
}

EDUCACIÓN FÍSICA EN LOS ÚLTIMOS AÑOS DE LA EDUCACIÓN BÁSICA, SUS FORMAS Y SUS LUGARES EN EL PROGRAMA ESCOLAR: UN ESTUDIO DE REVISIÓN

\author{
Natacha da Silva Tavares*, Elisandro Schultz Wittizorecki*, \\ Vicente Molina Neto*
}

Palavras chave: Educação Física. Currículo.

Educação.

Estudo de revisão.

Keywords: Physical Education. Curriculum. Education. Review study.
Resumo: Este estudo apresenta uma revisão da produção científica em que mapeamos o que vem sendo pesquisado, os conceitos que se têm construído e o que se tem publicado acerca da temática Educação Física nos anos finais do ensino fundamental e currículo escolar, bem como buscamos entender em que perspectivas esta temática vem sendo investigada. Foi realizada a busca de artigos em periódicos brasileiros disponíveis online, da área da Educação Física de estratos Qualis A2, B1 e B2.É possível compreender a partir desta revisão que a Educação Física vem se configurando de diferentes formas nas escolas e que os processos de construção curricular têm se efetivado de diversas maneiras. Neste sentido, é possível compreender a Educação Física no ensino fundamental no contexto brasileiro como plural e heterogênea.
Palabras clave: Educación Física. Currículo. Educación. Estudio de revisión.
Resumen: Este estudio presenta una revisión de la producción científica en el cual hicimos un levantamiento de lo que se viene investigando, los conceptos que se han construido y lo que se ha publicado sobre la Educación Física en los años finales de la enseñanza básica y sobre el currículo escolar. También hemos buscado entender las perspectivas bajo las cuales el tema ha sido investigado. La revisión se llevó a cabo mediante la búsqueda de artículos en revistas brasileñas de educación física disponibles en línea, del área de Educación Física de estratos Qualis A2, B1 y B2. Se puede entender a partir de esta revisión que la Educación Física se ha configurado de diferentes formas en las escuelas y que los procesos de construcción curricular se han efectuado de diversas maneras. En este sentido, es posible entender la Educación Física en la escuela primaria en el contexto brasileño como plural y heterogénea.
*Universidade Federal do Rio Grande do Sul. Porto Alegre, RS, Brasil. E-mail: natacha_760@ hotmail.com

Recebido em: 17-05-2016 Aprovado em: 22-01-2017

DOI: http://dx.doi.org/10.22456/1982-8918.62986 (c) (1) () Licence 


\section{INTRODUÇÃOO}

Realizamos uma revisão da produção científica em periódicos brasileiros da área de conhecimento da Educação e da Educação Física com o intuito de compreender o que vem sendo pesquisado, os conceitos que se têm construído e o que se tem publicado acerca da temática da Educação Física nos anos finais do ensino fundamental e o currículo escolar, bem como entender em que perspectivas esta temática vem sendo investigada.

As teorias e concepções de currículo são diversas. 0 currículo pode ser pensado, de modo limitado, como a configuração da grade de disciplinas, carga horária e seleção de conteúdos, mas também pode ser pensado a partir dos pressupostos e ideologias que pautam tais decisões e os processos empreendidos nas construções curriculares.

Quando se define/constrói um currículo, se transcreve e se endereça de forma implícita e explícita algumas funções para a escola, para os docentes e para os componentes curriculares. Assim, os pressupostos de um currículo expressam uma proposta de socialização dos sujeitos - com que saberes/culturas e de que forma(s) essa socialização é pensada.

\section{PERCURSO METODOLÓGICO}

A busca foi realizada em artigos de periódicos brasileiros online da área da Educação Física e da Educação, pertencentes ao Qualis da Área 211', com os estratos A2, B1 e B2².A procura foi realizada a partir do cruzamento do termo Educação Física Escolar com os seguintes descritores: conteúdo, currículo, saberes, sistematização, planejamento e construção curricular.

A partir desses descritores localizamos um total de 531 artigos. A fim de focalizarmos a leitura na temática de interesse da pesquisa, excluímos - para leitura do resumo - os artigos cujos títulos explicitassem claramente a temática da educação infantil, do ensino médio, do ensino superior ou da formação continuada; que tratassem de sistematização ou problematização de algum esporte ou conteúdo curricular específico; que focassem em questões fisiológicas ou biomecânicas; ou não tratassem de Educação Física Escolar. Assim, depois de feita esta exclusão realizamos a leitura de159 resumos.

Foi possível identificar, a partir da leitura desses resumos, uma vasta produção acerca da seleção e sistematização dos conteúdos para as aulas de Educação Física. Grande parte desses artigos tem como foco uma prática corporal específica - como jogos, lutas, dança ou esporte -, com fim de desmitificar as representações didático-metodológicas acerca do trabalho com alguma prática corporal, como os esportes, por exemplo, que eram abordados, em alguns artigos, no intuito de ampliar a compreensão sobre as diferentes possibilidades metodológicas de trabalhar com este conteúdo no ambiente escolar e suas funções pedagógicas. Outros conteúdos, como lutas e danças, foram alvo de pesquisas no ambiente escolar com o objetivo de proporcionar reflexões acerca da presença ou falta desses conteúdos no currículo das escolas.

Todos esses temas parecem bastante relevantes para pensar a temática da Educação Física no currículo escolar. Todavia, o fato desses estudos terem como foco uma prática corporal específica não possibilita: um debate mais amplo acerca da Educação Física na construção

1 Triênio 2013-2015.

2 Cabe esclarecer que não consta nenhum periódico brasileiro da área 21 no estrato A1. 
curricular da escola; a compreensão das relações destes conteúdos com outros componentes curriculares; a localização temporal e espacial deste conteúdo no planejamento em longo prazo; os aspectos micropolíticos envoltos no trabalho com diferentes práticas corporais.

Além disso, com base na leitura dos resumos pudemos observar que muitas temáticas potentes sobre a questão curricular, como "currículo multicultural" e "espaços da Educação Física no currículo", estão sendo abordadas através de ensaios, o que indica que as compreensões sobre o currículo na Educação Física - no Brasil - se encontram em um processo de transformação, de debate/discussão. Todavia, apesar de indicarem reflexões e problemáticas atuais sobre as questões curriculares, não permitem compreender o que vem sendo pensado e efetivamente realizado nas escolas.

A partir do exposto selecionamos 21 artigos para lermos integralmente, com base nos seguintes critérios:

- Abordam ou contemplam o ensino fundamental;

- Abordam a organização e as finalidades da Educação Física na escola;

- Não tratam da sistematização de apenas um conteúdo ou tema pedagógico;

- São fruto de pesquisa (análise documental, etnografias, pesquisas-ação, estudos descritivos, narrativas) e não ser ensaio ou revisão sistemática.

Para a leitura integral dos artigos organizamos um roteiro de perguntas a fim de possibilitar sua compreensão e síntese de modo a auxiliar na problemática do estudo. Este roteiro contou com as seguintes indagações:

- Com que perspectiva teórica o trabalho analisa o tema Currículo?

- Em que contexto/região o estudo foi realizado?

- Como o texto aborda os aspectos didático-metodológicos, objetivos e conteúdos?

- Como o texto aborda as demandas apresentadas nos documentos oficiais e as singularidades culturais das comunidades escolares?

- Quais estratégias e caminhos são percorridos na construção da Educação Física abordada neste texto?

- Qual o desenho teórico-metodológico adotado na pesquisa que origina o artigo?

A busca nos periódicos do Qualis com estratoA2 foi realizada no dia 26 de agosto de 2015. Os periódicos consultados foram: Revista Brasileira de Medicina do Esporte, Motriz: Revista de Educação Física, Movimento e Revista Saúde e Sociedade. No total foram selecionados para leitura completa oito artigos, expressos no quadro a seguir:

Quadro 1- Síntese dos artigos de revistas de estrato A2

\begin{tabular}{|l|l|c|c|c|}
\hline Periódicos & Descritores & No de artigos & № de resumos idos & No art. lidos \\
\hline \multirow{4}{*}{ Revista Brasileira } & Currículo & 0 & 0 & $x$ \\
de Medicina do & Conteúdo & 0 & 0 & $x$ \\
Esporte & Saberes & 0 & 0 & $x$ \\
& Sistematização & 0 & 0 & $x$ \\
& Planejamento & 0 & 0 & $x$ \\
& Construção curricular & 0 & 0 & $x$ \\
\hline
\end{tabular}


Continuação do quadro $1 .$.

\begin{tabular}{|l|l|c|c|c|}
\hline & Currículo & 2 & 2 & 0 \\
Motriz: Revista & Conteúdo & 1 & 1 & 1 \\
de Educação & Saberes & 95 & 5 & 3 \\
Física & Sistematização & 1 & 1 & 0 \\
& Planejamento & 1 & 1 & 0 \\
& Construção curricular & 0 & 0 & $x$ \\
\hline \multirow{5}{*}{ Movimento } & Currículo & 2 & 1 & 1 \\
& Conteúdo & 1 & 1 & 0 \\
& Saberes & 3 & 1 & 0 \\
& Sistematização & 1 & 1 & 1 \\
& Planejamento & 4 & 3 & 0 \\
\hline \multirow{5}{*}{ Saúde e } & Construção curricular & 0 & 0 & 0 \\
Sociedade & Currículo & 0 & 0 & 0 \\
& Conteúdo & 0 & 0 & 0 \\
& Saberes & 0 & 0 & 0 \\
\hline
\end{tabular}

Fonte: elaborado pela autoria

A busca nos periódicos de estrato $B 1$ foi realizada durante a primeira quinzena de outubro de 2015. A busca foi realizada nos periódicos: Currículo sem Fronteiras; Educação em Revista; Educação e Pesquisa; Horizontes Antropológicos; Paideia; Revista Brasileira de Ciências do Esporte; Revista Brasileira de Educação Física e Esporte; Revista Brasileira de Educação; Revista da Educação Física ${ }^{3}$. No total foram selecionados para leitura completa 12 artigos, expressos no quadro a seguir:

Quadro 2 - Síntese dos artigos das revistas com Qualis B1

\begin{tabular}{|c|c|c|c|c|}
\hline Periódicos & Descritores & № de artigos encontrados & № de resumos & № art. lidos \\
\hline $\begin{array}{l}\text { Currículo sem } \\
\text { fronteiras }\end{array}$ & $\begin{array}{l}\text { Currículo } \\
\text { Conteúdo } \\
\text { Saberes } \\
\text { Sistematização } \\
\text { Planejamento } \\
\text { Construção curricular }\end{array}$ & $\begin{array}{c}99 \\
6 \text { (repetidos) } \\
6 \text { (repetidos) } \\
4 \text { (repetidos) } \\
6 \\
1 \text { (repetido) }\end{array}$ & $\begin{array}{l}10 \\
6 \\
0 \\
0 \\
4 \\
0\end{array}$ & $\begin{array}{l}3 \\
0 \\
0 \\
0 \\
2 \\
0\end{array}$ \\
\hline $\begin{array}{l}\text { Educação } \\
\text { em Revista } \\
\text { (UFMG) }\end{array}$ & $\begin{array}{l}\text { Currículo } \\
\text { Conteúdo } \\
\text { Saberes } \\
\text { Sistematização } \\
\text { Construção curricular } \\
\text { Planejamento }\end{array}$ & $\begin{array}{l}0 \\
0 \\
0 \\
0 \\
0 \\
0\end{array}$ & $\begin{array}{l}0 \\
0 \\
0 \\
0 \\
0 \\
0\end{array}$ & $\begin{array}{l}0 \\
0 \\
0 \\
0 \\
0 \\
0\end{array}$ \\
\hline $\begin{array}{l}\text { Educação e } \\
\text { pesquisa USP }\end{array}$ & $\begin{array}{l}\text { Currículo } \\
\text { Conteúdo } \\
\text { Saberes } \\
\text { Sistematização } \\
\text { Planejamento } \\
\text { Construção curricular }\end{array}$ & $\begin{array}{l}0 \\
0 \\
0 \\
0 \\
0 \\
0\end{array}$ & $\begin{array}{l}0 \\
0 \\
0 \\
0 \\
0 \\
0\end{array}$ & $\begin{array}{l}0 \\
0 \\
0 \\
0 \\
0 \\
0\end{array}$ \\
\hline $\begin{array}{l}\text { Horizontes } \\
\text { Antropológicos }\end{array}$ & $\begin{array}{l}\text { Currículo } \\
\text { Conteúdo } \\
\text { Saberes } \\
\text { Sistematização } \\
\text { Planejamento } \\
\text { Construção curricular }\end{array}$ & $\begin{array}{l}0 \\
0 \\
0 \\
0 \\
0 \\
0\end{array}$ & $\begin{array}{l}0 \\
0 \\
0 \\
0 \\
0 \\
0\end{array}$ & $\begin{array}{l}0 \\
0 \\
0 \\
0 \\
0 \\
0\end{array}$ \\
\hline
\end{tabular}

Continua na próxima pagina...

3 Nome atual:Journal of Physical Education. 
Continuação do quadro $2 . .$.

\begin{tabular}{|c|c|c|c|c|}
\hline $\begin{array}{l}\text { Revista } \\
\text { Motricidade }\end{array}$ & $\begin{array}{l}\text { Currículo } \\
\text { Conteúdo } \\
\text { Saberes } \\
\text { Sistematização } \\
\text { Planejamento } \\
\text { Construção curricular }\end{array}$ & $\begin{array}{l}0 \\
0 \\
0 \\
0 \\
0 \\
0\end{array}$ & $\begin{array}{l}0 \\
0 \\
0 \\
0 \\
0 \\
0\end{array}$ & $\begin{array}{l}0 \\
0 \\
0 \\
0 \\
0 \\
0\end{array}$ \\
\hline Paideia & $\begin{array}{l}\text { Currículo } \\
\text { Conteúdo } \\
\text { Saberes } \\
\text { Sistematização } \\
\text { Planejamento } \\
\text { Construção curricular }\end{array}$ & $\begin{array}{l}2 \\
2 \\
0 \\
0 \\
0 \\
0\end{array}$ & $\begin{array}{l}2 \\
2 \\
0 \\
0 \\
0 \\
0\end{array}$ & $\begin{array}{l}0 \\
0 \\
0 \\
0 \\
0 \\
0\end{array}$ \\
\hline RBCE & $\begin{array}{l}\text { Currículo } \\
\text { Conteúdo } \\
\text { Saberes } \\
\text { Sistematização } \\
\text { Planejamento } \\
\text { Construção curricular }\end{array}$ & $\begin{array}{l}11 \\
27 \\
14 \\
11 \\
15 \\
20\end{array}$ & $\begin{array}{c}3 \\
27 \\
14 \\
11 \\
15 \\
20\end{array}$ & $\begin{array}{l}2 \\
0 \\
0 \\
0 \\
0 \\
0\end{array}$ \\
\hline $\begin{array}{l}\text { Revista } \\
\text { Brasileira de } \\
\text { Educação } \\
\text { Física e } \\
\text { Esporte }\end{array}$ & $\begin{array}{l}\text { Currículo } \\
\text { Conteúdo } \\
\text { Saberes } \\
\text { Sistematização } \\
\text { Planejamento } \\
\text { Construção curricular }\end{array}$ & $\begin{array}{c}2 \\
\text { 71. (10 repetidos) } \\
19 \\
\text { 3. (repetidos) } \\
49 \text { (muito repetidos) } \\
1 \text { (repetido) }\end{array}$ & $\begin{array}{c}2 \\
10 \\
5 \\
0 \\
0 \\
0\end{array}$ & $\begin{array}{l}0 \\
2 \\
2 \\
0 \\
0 \\
0\end{array}$ \\
\hline $\begin{array}{l}\text { Revista } \\
\text { Brasileira de } \\
\text { Educação }\end{array}$ & $\begin{array}{l}\text { Currículo } \\
\text { Conteúdo } \\
\text { Saberes } \\
\text { Sistematização } \\
\text { Planejamento } \\
\text { Construção curricular }\end{array}$ & $\begin{array}{l}0 \\
0 \\
0 \\
0 \\
0 \\
0\end{array}$ & $\begin{array}{l}0 \\
0 \\
0 \\
0 \\
0 \\
0\end{array}$ & $\begin{array}{l}0 \\
0 \\
0 \\
0 \\
0 \\
0\end{array}$ \\
\hline $\begin{array}{l}\text { Revista da } \\
\text { Educação } \\
\text { Física UEM }\end{array}$ & $\begin{array}{l}\text { Currículo } \\
\text { Conteúdo } \\
\text { Saberes } \\
\text { Sistematização } \\
\text { Planejamento } \\
\text { Construção curricular }\end{array}$ & $\begin{array}{c}4 \\
11 \\
2 \\
2 \\
8 \\
4\end{array}$ & $\begin{array}{l}1 \\
1 \\
1 \\
0 \\
2 \\
0\end{array}$ & $\begin{array}{l}0 \\
0 \\
0 \\
0 \\
1 \\
0\end{array}$ \\
\hline
\end{tabular}

Fonte: elaborado pela autoria

Nos periódicos de Qualis B2 o levantamento foi realizado no dia 16 de outubro de 2015, nos seguintes periódicos: Motrivivência e Pensar a Prática. A partir dos critérios estabelecidos foi selecionado um artigo para a leitura completa, como expressa o quadro a seguir:

Quadro 3 - Síntese dos Artigos de revistas com Qualis B2

\begin{tabular}{|l|l|c|c|c|}
\hline Periódico & Descritores & Artigos encontrados & Resumos lidos & Art. lidos \\
\hline \multirow{5}{*}{ Pensar a prática } & Currículo & 3 & 2 & 0 \\
& Conteúdo & 10 & 0 & 0 \\
& Saberes & 1 & 0 & 0 \\
& Sistematização & 4 & 1 & 0 \\
& Planejamento & 1 & 1 & 0 \\
& Construção curricular & 0 & 0 & 0 \\
\hline \multirow{5}{*}{ Motrivivência } & Currículo & 8 & 1 & 1 \\
& Conteúdo & 7 & 1 & 0 \\
& Saberes & 2 & 0 & 0 \\
& Sistematização & 1 & 0 & 0 \\
& Planejamento & 0 & 0 & 0 \\
& Construção curricular & 0 & 0 & 0 \\
\hline
\end{tabular}




\section{ANÁLISE E DISCUSSÃO}

A partir do roteiro de leitura apresentado acima foi possível agrupar os textos por temáticas que ilustram os temas de maior visibilidade acerca da Educação Física nos anos finais do ensino fundamental, suas configurações e seus lugares no currículo escolar. Assim, os textos foram agrupados pelas seguintes temáticas: seleção e sistematização de conteúdos (ROSÁRIO;DARIDO, 2005); produções e reproduções (NUNES; RÚBIO, 2008), (CRUZ; PALMEIRA, 2009),(CORSI; LIMA, 2010); currículos oficiais (TENÓRIO et al., 2012; 2015), (GALIAN; SAMPAIO, 2012), (GRAMORELLI; NEIRA, 2009); planejamento (MUÑOZ PALAFOX, 2004),(AMARAL, 2004), (ANTUNES; DANTAS, 2010), construção e organização curricular da Educação Física(EF)(OLIVEIRA et al., 2011); (ANTUNES et al., 2008), (VENÂNCIO; DARIDO, 2012); a EF no currículo escolar (BARTHOLO et al., 2011); a EF a partir da prática pedagógica (BARROS; DARIDO, 2009),(RODRIGUES; DARIDO, 2008), (SOUZA JÚNIOR; DARIDO, 2003),(NEIRA, 2008a); a EF em atividades extra turno (LUGUETTI et al., 2015), (ROCHA et al., 2009).

Quanto à primeira temática,"Seleção e Sistematização de Conteúdos",é possível identificar uma hegemonia dos esportes na seleção dos conteúdos para as aulas de EF, assim como aponta Frizzo (2012). O texto de Rosário e Darido (2005) advém de uma pesquisa qualitativa, através de revisão sistematizada e entrevistas semiestruturadas - que investigou a sistematização dos conteúdos da EF nas aulas de $5^{\text {a }}$ a $8^{a}$ séries do ensino fundamental. A partir das entrevistas, os autores apresentam diferentes entendimentos dos professores de EF sobre as finalidades deste componente curricular na escola e destacam as experiências de vida como um aspecto importante na formulação desses entendimentos.

Assim como no estudo de Betti (1999), os autores entendem que a hegemonia dos esportes como conteúdo da EF ocorre por diversas razões, possivelmente, pelos professores não se sentirem confiantes para trabalhar com conteúdos que não dominam motoramente; pelo gosto e preferência por estes conteúdos por parte dos estudantes; por um entendimento de que há cobrança da sociedade para que os estudantes dominem estes conteúdos; faltam materiais/espaços adequados para outras práticas. Esses elementos são deveras relevantes para o processo de construção curricular e, além disso, permitem refletir sobre os aspectos que permeiam essas decisões, como as experiências construídas pelos docentes, as representações acerca das funções da Educação Física na escola, a(s) cultura(s) docente(s) e juvenil, as expectativas da comunidade escolar/sociedade em relação ao ensino.

Ainda assim, outras práticas podem pertencer e compor o currículo da EF. Neira (2008b), por exemplo, propõe que a cultura corporal popular seja tema central na aula de Educação Física na perspectiva de um currículo multicultural. Através de um estudo realizado por meio de uma pesquisa-ação, Neira (2008b) mapeou as práticas e atividades que compunham a cultura corporal popular da comunidade estudada e propôs trabalhar com essestemas através de uma releitura e ressignificação dos signos relacionados a essaspráticas. Por meio de uma estratégia de ensino inspirada na etnografia, formulou-se um currículo multicultural para a Educação Física em que os estudantes e a comunidade foram sujeitos ativos e participantes do processo. Para o autor, além da relevância da cultura popular como conteúdo das aulas, a metodologia de ensino auxiliou na construção de uma postura crítica dos estudantes frente aos temas desenvolvidos, o que também permitiu maior receptividade e ampliação do leque de possibilidades de conteúdos a serem integrados ao currículo. 
Os estudos alocados na temática "Produções e Reproduções" evidenciam possíveis implicações do currículo na formação dos estudantes, na construção de identidades e subjetividades dos sujeitos em formação, bem como a relação entre as identidades docentes e a reprodução na identidade dos estudantes. Neste sentido, os artigos chamam a atenção para a necessidade da intencionalidade no processo de escolarização. A impossibilidade de haver neutralidade no processo de ensino-aprendizagem fica evidente na medida em que 0 ato pedagógico produz algo nos estudantes.

Cruz e Palmeira (2009) analisaram o plano de curso da disciplina de EF de uma escola. $O$ estudo assinala para a significância das aulas coeducativas na reconstrução de representações de gênero e de estereótipos nas aulas. Todavia, assim como no estudo de Souza Júnior e Darido (2003), a proposta de ensino coeducativo não se concretiza nas aulas. No entendimento dos autores, tanto a questão da seleção de conteúdos quanto a não efetivação da aula coeducativa precisa ser pensada pela ótica cultural, da construção cultural das representações e dos costumes.

Ainda que seja importante entendermos que diferentes elementos e fatores podem estar envoltos nessa forma de organização, cabe refletir sobre suas possíveis implicações na formação dos estudantes. É neste sentido que os autores anunciam que as decisões pedagógicas dos professores podem agir a favor ou contra a reprodução dos estereótipos de sexo e gênero.

Nunes e Rúbio (2008) também se atêm à questão da construção de identidade, porém, de uma forma mais ampla. Os autores fazem uma retomada histórica dos diferentes currículos propostos para a EF analisando e problematizando que sujeitos se pretendia formar a partir destes currículos e estes entendem que o fato da EF ter tido diferentes propostas dificulta a construção de uma identidade para esta disciplina na escola, e também o reconhecimento de seu papel na escola e, assim, os professores acabam por assumir diferentes funções. A identidade dos professores é aspecto significativo uma vez que está relacionada e conectada às interpretações e decisões dos docentes na construção curricular.

Nesta mesma linha, no estudo de Corsi e Lima (2010) buscou-se compreender as questões de diferença cultural no ensino fundamental, através de observações e entrevistas. A análise e a reflexão do estudo se fundamentam na perspectiva do Multiculturalismo e, assim, 0 texto apresenta uma constante discussão entre a prática pedagógica e o currículo. Segundo Corsi e Lima (2010), o debate acerca da construção das diferenças a partir do gênero, da sexualidade e das culturas localiza-se, no contexto estudado, em um espaço/tempo determinado/pontual, deslocado para fora do tempo habitual de aula, como feiras e apresentações, indicando certa desconexão desses temas com os conhecimentos tratados cotidianamente. Os autores apontam, ainda, que algumas cenas/fatos que poderiam ser potentes para a realização de um debate com os estudantes passam, por vezes, despercebidas e/ou não têm uma reflexão aprofundada, pedagogizada. No seu entendimento, um trabalho adequado e consistente necessita do apoio da administração escolar e de condições para que os docentes se apropriem e adquiram os saberes necessários para este trabalho.

Os artigos que têm como temática os "Currículos Oficiais" apresentam análises dos pressupostos que sustentam algumas propostas de ensino, tratam de apresentações e problematizações sobre construções de currículo, bem como da incorporação destas propostas no cotidiano das escolas. 
Os estudos de Tenório et al. (2012; 2015) e Galian e Sampaio (2012) trataram de abordar os pressupostos e as implicações de propostas de ensino e curriculares. Tenório e colaboradores (2012) realizaram uma análise da coerência interna entre as intencionalidades e as avaliações contidas em propostas curriculares estaduais paraEF do Sudeste brasileiro. Os autores identificaram incoerência entre as intencionalidades pedagógicas presentes em propostas curriculares oficiais e as avaliações elaboradas em nível nacional ou presentes nas propostas. Tendo em vista que se trata de um estudo realizado a partir de análise documental, não é possível conceber como esses currículos são recebidos, interpretados e apropriados pela escola. Ainda assim, esses achados apontam para a coexistência de diferentes propostas e concepções de ensino, ao passo em que as propostas curriculares indicam a formação para a cidadania, para a autonomia e emancipação e as avaliações carregam consigo uma lógica meritocrática. Esta presença de contradição nas formulações curriculares não parece ser, todavia, incongruente, considerando-se que os projetos de formação/ensino são disputados diariamente a partir de diferentes entendimentos, interesses e projeções de mundo. Neste sentido, as contradições e disputas se apresentam como dimensões expressivas para se pensar os elementos que constituem a construção curricular.

Em outro estudo, Tenório et al. (2015) objetivaram analisar como o tema esporte foi abordado nas propostas curriculares para EF no estado de Pernambuco de 1989 a 2013. Os autores identificaram que as propostas curriculares foram participativas. 0 estudo indica que 0 objeto de estudo/ensino da EF nessas propostas é a cultura corporal, mas que a construção de uma metodologia adequada e coerente com esta perspectiva para o trabalho com os esportes ainda se encontra em construção e reflexão, em razão de o esporte ser associado ao alto rendimento.

Galian e Sampaio (2012) se propõem a discutir sobre as implicações das propostas de educação em tempo integral, a partir da análise de algumas propostas oficiais. Os autores diferem "educação integral" de "educação em tempo integral", em que a primeira preconiza a formação geral e integral dos sujeitos, enquanto a segunda trata de oferecer uma educação formal durante um tempo alargado. A partir desta reflexão problematizam os pressupostos que guiam estas propostas. Segundo os autores não basta propor um alargamento do tempo na escola,mas, sim, clarificar quais currículos, conhecimentos e formas. Neste sentido, as análises de Galian e Sampaio (2012) ajudam a pensar sobre os pressupostos que antecedem uma proposta oficial, as concepções em que as mudanças educacionais se ancoram, em nível local ou mais amplo e, ainda, permitem refletir sobre em que medida os modelos, tempos/ espaços e configurações escolares têm tido êxito para o projeto de formação dos sujeitos.

Pensando na relação entre currículo oficial e currículo em ação, Gramorelli e Neira (2009) averiguaram possíveis apropriações dos pressupostos teórico-metodológicos contidos nos Parâmetros Curriculares Nacionais de EF pelos professores dos anos finais do ensino fundamental depois de dez anos da criação do documento. A pesquisa foi realizada através da análise de conteúdos dos PCN e Grupo Focal com professores. Os autores apontaram para uma transformação na concepção dos professores sobre a EF na escola, aproximando-se do que os parâmetros propunham, a inclusão de objetivos e conteúdos conceituais e um entendimento de avaliação como parte do processo pedagógico. Salientam que não é possível saber se esses posicionamentos ocorrem em razão da publicação do documento. Ainda assim, as propostas dos PCN parecem ser a culminância de debates e reflexões da área, em que os entendimentos e concepções construídos por professores e teóricos, na época, foram assumidos em nível nacional, apresentando-se como um caminho possível para a formulação de currículos oficiais. 
A partir destes estudos é possível identificar o distanciamento/aproximação entre as propostas e o cotidiano e compreendê-los como parte do processo de mudança e de construção de um projeto de ensino.

O "Planejamento" aparece como uma das temáticas por ser entendido como uma etapa ou movimento significativo do processo curricular. Em alguns estudos o planejamento é proposto como estratégia de formação continuada e como forma de construção de uma prática pedagógica mediadora e intencional.

Muñoz Palafox (2004) analisou os elementos constitutivos de uma abordagem crítica de planejamento de ensino e descreveu a realização de um Planejamento Coletivo do Trabalho Pedagógico - realizado através da assessoria do Núcleo de Estudos em Planejamento e Metodologias de Ensino da Cultura Corporal (NEPECC/UFU) à Rede Municipal de Ensino de Uberlândia. $O$ autor narra que este planejamento coletivo foi construído como proposta de formação continuada de professores de uma escola de Uberlândia. No entanto, explica que não intencionou, nesse texto, analisar e relatar a experiência desse planejamento coletivo e sim apontar as diretrizes e conceitos construídos com vistas a possibilitar esse planejamento.

As perspectivas adotadas pelo autor para conceituar o planejamento crítico indicam uma semelhança com algumas concepções de currículo, pois o tratam como algo amplo, como um fazer político no trabalho docente. Neste sentido, é possível pensar: o que define/ caracteriza "currículo" e "planejamento"? Ainda assim, o texto apresenta alguns apontamentos interessantes, alguns obstáculos e algumas possíveis estratégias para superá-los. A partir disso, algumas diretrizes são sinalizadas a fim de viabilizar tal trabalho coletivo, como a criação de espaço/tempo, a disponibilização de especialistas para assessoramento e orientação, criação de espaço permanente de reflexão e estudo, realização de eventos, de diagnóstico de dificuldades e construção de uma proposta curricular compartilhada.

No entendimento do autor, os hábitos e costumes dos professores -muitas vezes acostumados à repetição de modelos - dificultam 0 ato de criação, tornando-se um obstáculo para o planejamento coletivo. A fim de superar este obstáculo foi proposta a definição de conceitos, para serem compartilhados pelos docentes e que servissem de base para 0 planejamento. Para o autor, esses conceitos vão sendo melhor compreendidos pelos docentes na medida em que estes vão se apropriando das diretrizes e organizando suas estratégias através da escrita, que se apresenta como uma potente tática para que os docentes avaliem a proximidade/distanciamento entre suas estratégias de ensino e os objetivos estabelecidos inicialmente no planejamento. O estudo de Amaral (2004), como o de Muñoz Palafox, é fruto de assessoramento do NEPECC/UFU à Rede Municipal de ensino de Uberlândia. Através de um planejamento coletivo, em que trataram da temática de produção do currículo da EF, realizaram uma formação continuada. A autora relata que esse assessoramento surgiu por uma iniciativa dos professores de EF da rede que sentiram a necessidade de uma orientação especializada para formularem uma Proposta Curricular para a EF. Esse ponto parece de grande relevância, pois indica 0 interesse dos professores em aprofundar seus conhecimentos, bem como um processo que surge da necessidade do trabalho e não por uma imposição verticalizada. 0 trabalho também comunica e exemplifica alguns movimentos para a viabilização de um planejamento coletivo, como a reconfiguração de horários e dias de aula a fim de propiciar aos professores um momento comum disponibilizado para reuniões. 
Amaral (2004) apresenta que a primeira versão do currículo para a EF definiu como temas para este componente curricular o esporte, o jogo, a dança e a ginástica. Todavia, como enfatiza a autora, não se pode apreender a materialização deste currículo apenas através do seu registro formal, oficial, mas, sim, olhando para a totalidade deste currículo, do currículo "em ação", como nomeia. Assim, no texto, apresenta diferentes movimentos feitos pelos docentes ao concretizarem o currículo no cotidiano das aulas, indicando seus entendimentos e interpretações acerca do que estava prescrito.

O estudo de Antunes e Dantas (2010) buscou validar ${ }^{4}$ uma proposta de estruturação para os conhecimentos da EF Escolar, através de um processo coletivo. Os autores propõem três dimensões a serem abordadas: sociocultural, biodinâmica e comportamental. Através da apresentação e validação da proposta pelos docentes o estudo reflete a diversidade de concepções e pressupostos que orientam as aulas, pois o posicionamento dos docentes foi bastante variado frente às propostas; alguns questionavam o aspecto de complexidade dos objetivos para o ensino fundamental, outros discordavam do aprofundamento conceitual proposto para alguns temas, ou mesmo a escolha dos temas.

A partir desses estudos é possível compreender o planejamento como parte do processo de construção curricular - apesar de em alguns estudos não ficar clara a diferença entre planejamento e currículo - e os dilemas e possibilidades de construção do planejamento. A partir das leituras desses artigos e de outros textos (GOODSON, 2012; SILVA, 2011) entendemos que currículo e planejamento se diferenciam pelo aspecto de concretude e subjetividade. Enquanto o planejamento tem a função de organizar os conteúdos e aprendizagens no tempo e no espaço escolar, o currículo tem funções mais subjetivas e de subjetivação, como produzir efeitos e significados nos sujeitos através de processos menos concretos, através da assimilação de costumes e da naturalização de processos e normas.

Os artigos da temática "Construção e organização Curricular da EF"estão alocados neste grupo em função da busca por vincular a EF com o restante da escola. Venâncio e Darido (2012) consideram o Projeto Político Pedagógico (PPP) como um instrumento potente para participação e envolvimento dos professores de EF. Os autores enfatizam que a construção coletiva do PPP pode ser um processo que auxilia a sustentar uma proposta mais coerente com as funções da escola e do ensino, possibilitando a construção de uma identidade para a EF que se articule com o restante da escola.

O estudo de Oliveira et al. (2011)investigou como os professores de EF consideram e traduzem o PPP em aula. Através de um estudo descritivo, os autores observaram um movimento antagônico dos docentes, pois, segundo eles, estes demonstravam um entendimento consistente acerca das finalidades do PPP para a sustentação das aulas, mas a materialização desses pressupostos nas aulas pareceu não acontecer. Os autores consideram que essa incongruência se dê possivelmente em função de nem todos os agentes terem participado da construção do PPP,não tendo seus entendimentos contemplados. Também consideram que uma dificuldade de adaptação e criação por parte dos docentes pode auxiliar na distância entre o PPP e a prática pedagógica. Além disso, os autores entendem que o PPP precisa servir de suporte para a prática pedagógica e não como um manual e, assim, é esperado que haja tal distanciamento. Ademais, este documento necessita não ser fixo/rígido, mas, sim, cambiante. 
Em congruência, Antunes et al. (2008) enfatizam que é necessário construir uma EF que afine seus objetivos com as propostas educacionais, de forma que não the seja relegada uma função de recreação na escola.Assim, os autores propõem uma organização curricular coletiva, pautada em uma perspectiva crítica, como estratégia de formação continuada para os professores de EF. Algumas dificuldades foram encontradas pelos pesquisadores nesse processo, como a alta rotatividade dos docentes da rede, sobrecarga de trabalho e carga horária que dificultava as reuniões; e a não identificação dos docentes com a proposta de formação continuada. Apesar de todas as dificuldades, conseguiu-se construir uma organização curricular para a EF. Não fica claro, todavia, como a organização e os pressupostos elaborados para a EF se articulam com a proposta da escola.

A "EF no Currículo Escolar" foi foco de pesquisa do estudo de Bartholo et al. (2011). Através da análise de cinco dissertações de mestrado os autores buscaram compreender os dilemas da EF no território curricular das escolas. Identificaram que à EF cabe - nos contextos da pesquisa - a construção de valores para a formação dos estudantes que lhes permitam atuar na vida pública. A partir deste foco na construção de valores os autores apontam que há um deslocamento dos conhecimentos específicos da disciplina, o que acarreta uma busca constante por seu reconhecimento e valorização no universo escolar. Uma vez que a EF parece ser entendida como lazer passa a receber um menor reconhecimento na escola, visto que os seus saberes não parecem atender às necessidades do mercado de trabalho. Neste sentido, o estudo aponta para uma falta de articulação entre a EF, o contexto escolar e os objetivos de ensino.

Assim, o texto auxilia a compreender alguns elementos que estão para além da rotina da escola e das intencionalidades pedagógicas e que fazem parte da construção e da configuração de uma disciplina no currículo escolar, como as relações de poder, as representações sociais construídas acerca de determinados saberes, as expectativas micro e macrossociais de formação pessoal e profissional. Neste sentido, pensar o(s) lugar(es) que a Educação Física ocupa no currículo escolar implica repensar as fronteiras do universo escolar; é pensar para além das decisões individuais e locais, considerar o currículo como efeito de políticas e relações mais amplas e também como uma produção possível, relacionando os aspectos micro/locais com o contexto macrossocial.

Em outros estudos a "prática pedagógica" aparece como elemento central para a construção de um currículo, pois os autores consideram que é na prática pedagógica que se colocam em ação as propostas de ensino. Em pesquisa etnográfica realizada por Barros e Darido (2009) - que investigou, na prática pedagógica de dois professores de EF,os conteúdos conceituais e as estratégias de ensino utilizadas - identificou-se que as estratégias mais utilizadas pelos docentes para trabalhar a dimensão conceitual foram debates, exposições, discussões, reflexões sobre a prática e resolução de problemas. É importante destacar que, segundo os autores, estas estratégias foram bem recebidas pelos estudantes e que, assim, se apresentam como um caminho possível para uma reconstrução de paradigma da área.

A prática pedagógica aparece nos estudos de Rodrigues e Darido (2008) e Souza Júnior e Darido (2003) como ponto central para a configuração de uma EF que supere o modelo tradicional de ensino. O planejamento, a avaliação e as estratégias didáticas se apresentam como elementos importantes para sustentar e auxiliar na construção de uma prática pedagógica que considere a aprendizagem da dimensão conceitual, procedimental e atitudinal na EF, bem como na reconstrução de representações de gênero e desconstrução de preconceitos. 
Neira (2008a) buscou, em seu estudo, promover uma reflexão dos professores atuantes em contextos escolares sobre suas práticas pedagógicas. 0 estudo foi realizado através de uma etnografia, em duas escolas portuguesas que atendem comunidades multiculturais, segundo 0 autor. $\mathrm{O}$ autor identificou que as práticas pedagógicas dos professores estavam bastante centradas no controle e na condução das tarefas/atividades; privilégio e diferenciação entre os estudantes. Para Neira (2008a),essas formas de configuração da prática pedagógica expressam/evidenciam um entendimento acerca do papel da escola que tem como pressuposto um lugar de superioridade dos docentes, sendo estes aqueles que dominam e detêm os saberes legítimos de serem transmitidos. $O$ autor entende que a prática pedagógica dos docentes colaboradores se associa a uma concepção de multiculturalismo conservador, pautado num discurso de que todos são iguais e têm as mesmas condições, acarretando um currículo unificado. Apesar disso, o estudo aponta para ações de resistência por parte dos estudantes à inculcação da cultura dominante na escola, como a negação aos conteúdos. 0 estudo apresenta e retoma interessantes e centrais questões acerca do currículo analisando os saberes valorizados na escola e os saberes construídos em contextos culturais diversos e como estes são tratados na prática pedagógica dos professores. Todavia, como o próprio autor aponta, seria limitado localizar os problemas e dilemas do currículo nos docentes, uma vez que estes sujeitos também são construídos pelas subjetividades do processo de socialização e formação. Assim, apesar de o estudo apresentar elementos relevantes para se pensar a construção curricular, e passíveis de serem relacionados com o contexto brasileiro, entendemos que o olhar centrado na prática pedagógica dos professores pode anuviar outros elementos que vão para além das decisões dos docentes e que também configuram o currículo.

Por fim, os estudos vinculados à temática "A EF em atividades extraturno" levam a considerar as atividades extraturno, relacionadas à $E F$, como parte da construção e dos lugares desta disciplina na escola, uma vez que estes estudos surgiram a partir da busca com os descritores "educação física escolar" e "currículo", e "educação física escolar" e"conteúdo" respectivamente.

Luguetti et al. (2015) analisaram o planejamento das práticas esportivas escolares (PEE) no ensino fundamental no município de Santos (SP), através da aplicação de questionários com professores de escolas estaduais, municipais e particulares. Os autores enfatizam as diferenças e especificidades das PEE e das aulas de EF, mas entendem que as PEE ofertadas como atividades extraescolares precisam ser pautadas no PPP da escola e podem ser complementares às aulas. Todavia, identificam que em alguns projetos as práticas construídas são excludentes e seletivas, não sendo, assim, coerentes com a formação proposta para crianças e jovens da Educação Básica. Tais conclusões, no entanto, advindas de questionários, não permitem cotejar outras informações a fim de uma compreensão mais aprofundada acerca deste fenômeno. Ainda assim, entendo que este estudo anuncia, mesmo que de forma sutil, a participação das atividades extraescolares (dentro da escola) na composição e configuração de um currículo. Cabe pensar e compreender como essas atividades se articulam com as aulas de EF e com o projeto de formação da escola.

No estudo de Rocha et al. (2009) analisaram-se as formas de interação social possíveis nas aulas de EF a partir de uma proposta pedagógica pautada nas aulas abertas. A pesquisa se deu através de observações participantes com turmas de crianças de 9 a 11 anos em uma escola de ensino não formal. As aulas observadas eram parte do Programa de 
Desenvolvimento e Integração de Crianças e Adolescentes (Prodecad). Apesar de o estudo não tratar especificamente e com profundidade a temática do currículo escolar, evidencia a necessidade de haver congruência entre as propostas de ensino, os conteúdos e a metodologia de ensino tanto os espaços regulares de aula como nas atividades extraturno para que se atinjam os objetivos estabelecidos, assim como sugere Moreira (1997).

Retomamos que esses estudos permitem ampliar o olhar para o currículo para além dos momentos formais e regulares das aulas. É possível considerar que parte da configuração e dos lugares simbólicos da EF, bem como dos professores de EF, se dê em relação às diversas atividades e práticas relacionadas à área da EF que pertencem e acontecem no universo escolar.Tal entendimento se aproxima do que propõem Nunes e Rúbio (2008) ao exporem que o currículo compreende tudo que acontece no processo de escolarização, no processo de formação dos estudantes.

É possível compreender a partir desses diferentes estudos que a EF, mais especificamente nos anos finais do ensino fundamental, vem se configurando de diferentes formas e por diferentes percursos. Neste sentido, é possível compreender a EF no ensino fundamental no contexto brasileiro como plural e heterogênea. Tal configuração permite a construção de um leque de representações e significados para tal disciplina no contexto escolar, acerca de suas funções e de seus modos. A discussão sobre a questão curricular na/ da Educação Física, neste sentido, parece, então, delicada e permeada de tensões, uma vez que o debate não trata apenas da organização de conteúdos no tempo-espaço escolar, mas apresenta como pano de fundo uma gama variada de entendimentos acerca do papel desta disciplina no currículo, assim como diversas definições de seus conteúdos e saberes legítimos.

Alguns elementos parecem significativos para a configuração deste cenário, como as individualidades/identidades de docentes, gestores escolares e estudantes; a formação inicial e continuada dos docentes; os pressupostos das propostas curriculares oficiais, bem como 0 percurso adotado para sua implementação; as condições estruturais/materiais e de pessoal; a cultura e a história da comunidade escolar; a relação estabelecida entre as culturas locais e 0 contexto macrossocial.

Apesar de apresentar essa pluralidade, algumas formas e entendimentos de EF prevalecem no universo escolar e acabam por constituir uma identidade quase hegemônica para a disciplina. Uma dessas formas se constrói pelo entendimento de EF como sinônimo de esporte - de prática de esporte, pautada no saber fazer. Neste sentido, outras práticas ou configurações são entendidas como inovadoras, criativas, exceções, e não como composição de um todo.

\section{CONSIDERAÇÕES TRANSITÓRIAS}

Esta revisão permitiu identificar diferentes temáticas que podem auxiliar na compreensão do processo de construção curricular, como seleção de conteúdos, implicação das decisões pedagógicas na (re)construção de representações de gênero/etnia/classe, formas de avaliação, aspectos didático-metodológicos, objetivos de ensino, planejamento, concepções de ensino e de EF.

No entanto, há pouca articulação, nesses estudos, entre todos esses elementos. Muitos desses textos abordam a temática do currículo, todavia, não como categoria central de 
discussão. Outros trabalhos, apesar de terem o currículo como foco de debate- utilizando-se de referenciais críticos e pós-críticos para entender e conceituar o currículo -, limitam-se, nas análises, a compreender e dialogar sobre a seleção de conteúdos e os aspectos didáticos e de planejamento, não aprofundando a reflexão acerca das concepções de ensino, de corpo, de gênero e de classe que alicerçam tais decisões, bem como suas possíveis implicações nas formações dos sujeitos.

Entendemos que, ao tratarmos desses temas, estaremos, de alguma forma, ligados à temática curricular. Todavia, consideramos que compreender a construção curricular de uma escola demanda entender e relacionar todos esses aspectos conjuntamente. Compreender os aspectos simbólicos e singulares que configuram esse processo, como a cultura escolar, as representações elaboradas acerca do ensino, da escola, da Educação Física; as expectativas de toda a comunidade escolar; as experiências e conhecimentos de docentes e estudantes; as demandas de documentos oficiais.

Alguns dos estudos parecem tomar o currículo como sinônimo de documento, em que se explicita o planejamento e a organização do trabalho da EF referente aos conteúdos abordados. Neste sentido, os estudos parecem se dar na busca por identificar os conteúdos trabalhados nas aulas e/ou na tentativa de propor/auxiliar na elaboração de um currículo documentado que organize o trabalho da EF. Carece de uma compreensão acerca de como a EF vem se produzindo no currículo escolar. Ou seja, o olhar tem estado mais voltado para 0 currículo da EF na escola do que para a EF no currículo da escola.

É possível relembrar, ainda, a multiplicidade de entendimentos e o não consenso que permeia nossa sociedade e os diferentes contextos escolares. Pensar a Educação Física Escolar implica compreender estes diferentes cenários e contextos escolares, além de refletir e entender como as propostas de Educação Física na escola se articulam com as propostas e concepções de ensino que orientam os currículos escolares.

\section{REFERÊNCIAS}

AMARAL, Gislene Alves. Planejamento de currículo na Educação Física: possibilidades de um projeto coletivo para as escolas públicas de Uberlândia/Minas Gerais. Movimento, v. 10, n. 1, p. 133-155, jan./abr. 2004.

ANTUNES, Fabia Helena Chiorboli; DANTAS, Luiz. Sistematização do conhecimento declarativo em educação física escolar de $5 \mathrm{a}$ à 8 a séries do ensino fundamental. Revista Brasileira de Educação Física e Esporte, v.24, n.2, p.205-221, abr./jun. 2010.

ANTUNES, Marina Ferreira de Souza; AMARAL, Gislene Alves; LUIZ, Ângela Rodrigues. Proposta Curricular para a Educação Física: uma experiência a partir da formação continuada. Motrivivência, v.20, n.31, p. 143-162, dez.2008.

BARROS, André Minuzzo de; DARIDO, Suraya Cristina. Práticas pedagógicas de dois professores mestres em educação física escolar e o tratamento da dimensão conceitual dos conteúdos. Revista Brasileira de Educação Física e Esporte, v.23, n.1, p.61-75, jan./mar. 2009. 
BARTHOLO, Tiago Lisboa; SOARES, Antonio Jorge Gonçalves; SALGADO, Simone da Silva.

Educação Física: dilemas da disciplina no espaço escolar. Currículo sem fronteiras, v.11, n.2, p. 201-220, 2011.

CORSI, Adriana Maria; LIMA, Emília Freitas de. Práticas Pedagógicas no Ensino Fundamental na Perspectiva do Multiculturalismo Crítico. Currículo sem Fronteiras, v.10, n.2, p.158-182, jul./dez. 2010.

CRUZ, Marlon Messias Santana; PALMEIRA, Fernanda Caroline Cerqueira. Construção de identidade de gênero na Educação Física Escolar. Motriz, v.15, n.1, p.116-131, jan./mar. 2009.

FRIZZO, Giovanni Felipe Ernst. A organização do trabalho pedagógico da Educação Física na escola capitalista. 2012. 232f. Tese (doutorado em Ciências do Movimento Humano) - Escola de Educação Física, Universidade Federal do Rio Grande do Sul, UFRGS, Porto Alegre, 2012.

GALIAN, Cláudia Valentina Assumpção; SAMPAIO, Maria das Mercês Ferreira. Educação em Tempo Integral: implicações para o currículo da escola básica. Currículo sem Fronteiras, v. 12, n. 2, p. 403422, maio/ago. 2012.

GRAMORELLI, Lilian Cristina; NEIRA, Marcos Garcia. Dez anos de parâmetros curriculares nacionais: a prática da Educação Física na visão dos seus autores. Movimento, v. 15, n. 4, p. 107-126, out./dez. 2009.

LUGUETTI, Carla Nascimento et al. O planejamento das práticas esportivas escolares no ensino fundamental na cidade de Santos. Revista Brasileira de Ciências do Esporte, v. 37, n. 4, p.314-322, 2015.

MOREIRA, Antônio Flávio Barbosa. Currículos e programas no Brasil. 3.ed. Campinas : Papirus, 1997.

MUÑOZ PALAFOX, Gabriel Humberto. Planejamento coletivo do trabalho pedagógico da Educação Física - PCTP/EF como sistemática de formação continuada de professores: a experiência de Uberlândia. Movimento,v. 10, n. 1, p. 113-131, jan./abr. 2004.

NEIRA, Marcos Garcia. A Educação Física em Contextos Multiculturais: concepções docentes acerca da própria prática pedagógica. Currículo sem fronteiras, v.8, n.2, p.39-54, 2008 a.

NEIRA, Marcos Garcia. A cultura corporal popular como conteúdo do currículo multicultural da Educação Física. Pensar a Prática, v.11, p. 81-89, jan./jul. $2008 \mathrm{~b}$.

NUNES, Mário Luiz Ferrari; RÚBIO, Kátia. O(s) Currículo(s) da Educação Física e a Constituição da Identidade de seus Sujeitos. Currículo sem Fronteiras, v.8, n.2, p.55-77, 2008.

OLIVEIRA, Amauri Aparecido Bássoli et al. Projeto Político Pedagógico: elaboração e aplicação nas escolas públicas de Maringá. Movimento, v. 17, n.1, p. 77-94, jan./mar. 2011.

ROCHA, Braulio; WINTERSTEIN, Pedro José; AMARAL, Silvia Cristina Franco. Interação social em aulas de Educação Física. Revista Brasileira de Educação Física e Esporte, v.23, n.3, p.235-245, jul./set. 2009.

RODRIGUES, Heitor de Andrade; DARIDO, Suraya Cristina. As três dimensões dos conteúdos na prática pedagógica de uma professora de Educação Física com mestrado: um estudo de caso.

Revista da Educação Física/UEM, v. 19, n. 1, p. 51-64, 1. trim. 2008. 
ROSÁRIO, Luís Fernando Rocha; DARIDO, Suraya Cristina. A sistematização dos conteúdos da educação física na escola: a perspectiva dos professores experientes. Motriz, v.11, n.3, p.167-178, set./dez. 2005.

SILVA, Tomaz Tadeu. Documentos de Identidade: uma introdução às teorias do currículo. Belo Horizonte: Autêntica, 2011.

SOUZA JÚNIOR, Osmar Moreira; DARIDO, Suraya Cristina. Influências da cultura escolar no desenvolvimento de propostas coeducativas em aulas de Educação Física. Motriz, v.9, n.3, p.143151, set./dez. 2003.

TENÓRIO, Kadja Michele Ramoset al. Propostas curriculares Estaduais para Educação Física: uma análise do binômio intencionalidade-avaliação. Motriz, v.18, n.3, p.542-556, jul./set. 2012.

TENÓRIO, Kadja Michele Ramos. Propostas curriculares para Educação Física em Pernambuco: entendimentos acerca do esporte. Revista Brasileira de Ciências do Esporte, v. 37, n. 3, p.280-288, 2015.

VENÂNCIO, Luciana; DARIDO, Suraya Cristina. A educação física escolar e o projeto político pedagógico: um processo de construção coletiva a partir da pesquisa-ação. Revista Brasileira de Educação Física e Esporte, v.26, n.1, p.97-109, jan./mar. 2012. 